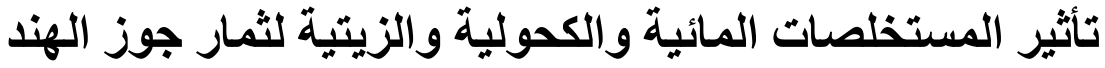 \\ Cocos nucifera L. والحروق
}

حلا مؤبا رديف

استلام البحث 27، تموز ، 2011

قبول النشر 12، تشرين الثناني، 2011

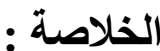

حضرت ثنلاثة أنواع من المستخلصات هي (المائية، الكحولية، الزيتية) من ثمار جوز الهند واجريت مجموعة الكيات

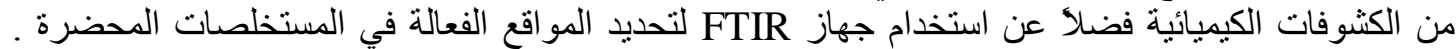

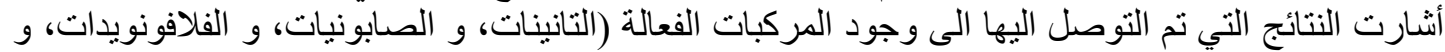

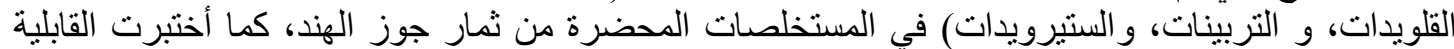

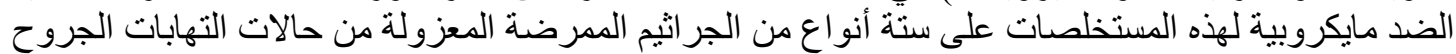

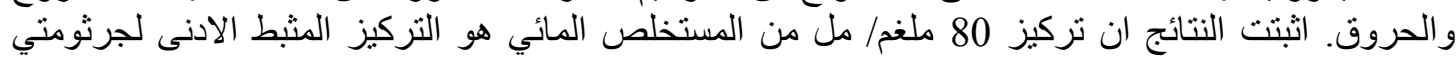

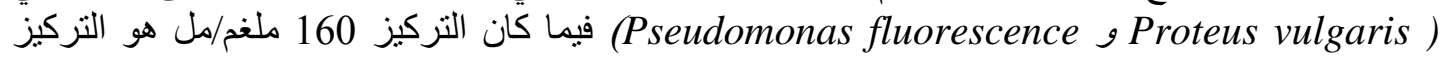

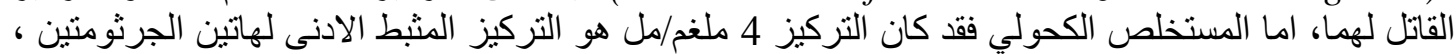

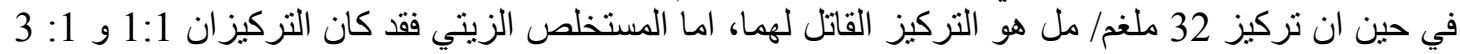

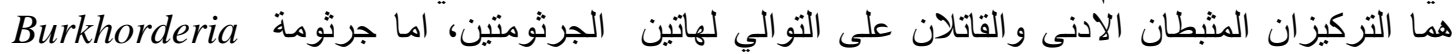
mallei

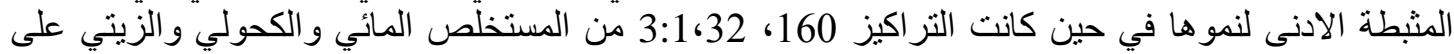
التو الي هي التز اكيز القاتلة لها.

الكلمات المفتاحية : زيت جوز الهند ، التهابات الجروح.

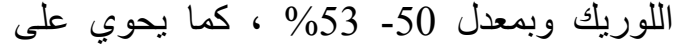
احماض دهنية منوسطة السلسلة (MCFA) من

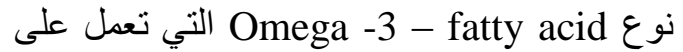

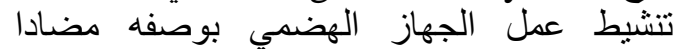

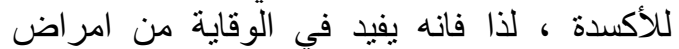

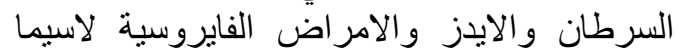

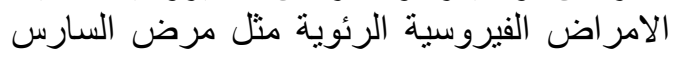

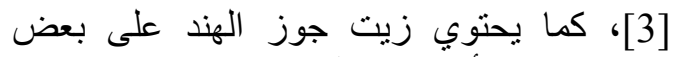

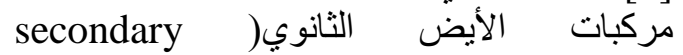
، metabolites ،الفلافونويدات ،القلويدات، التربينات، الستيرويدات)

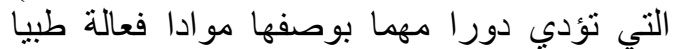

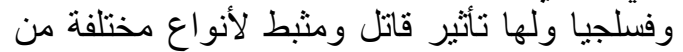

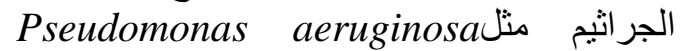
ويمكن استعمالها في علاج الكثيرمن الامر اض اضلتهن لفعاليتها وكونها توفر الجانب الآمن من الاستخدام

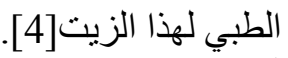

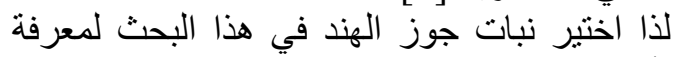

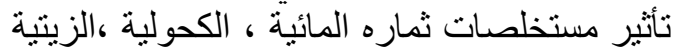
في نمو بعض الجر اثيم المعزولة من خمج الجروح ، الميلة

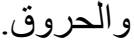

المقدمة -

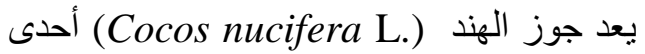

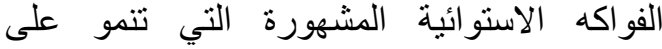

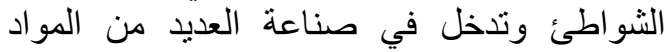
الغذائية و التجميلية ويسمى النارجيل فيل النيل او (جوز الهند)

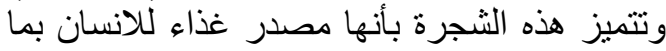

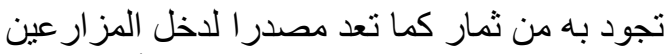

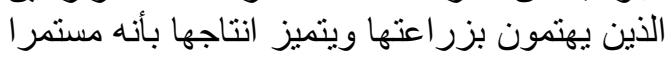
على مدار السنة [1].

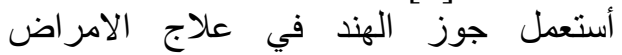

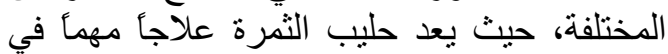

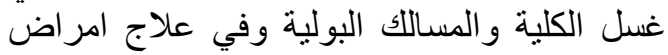

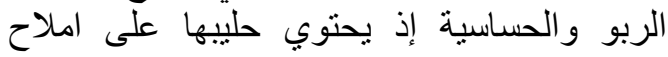

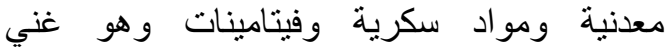

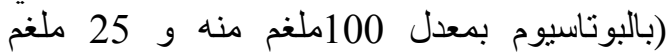

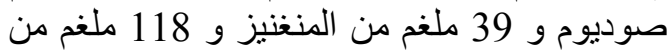

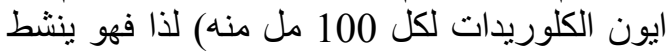

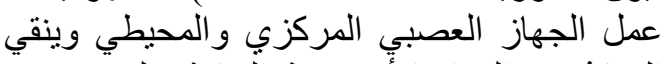

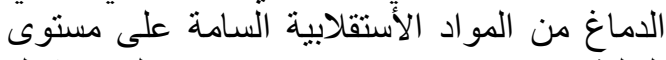

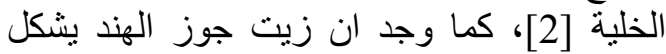

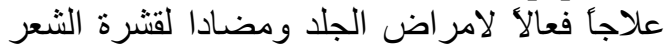

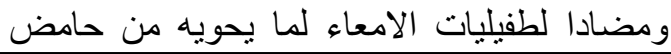


الاستخلاص الزيتي (Soxhlet) السكسوليت اذ تمت عملية الاستخلاص باستخدام المذيب الإني القطبي ثنائي اثيل الإيثر (Diethyle ether)

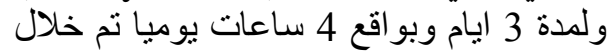
هذه المدة استخلاص الزيت الثابت الثابت من النبات وكذللك عملية الاسترجاع ثم جمع الزيت في في في بيكر زجاجي نظيف ومعقم وضع في في حاضنة عند درجة حرارة 37م للتخلص من في بقايا

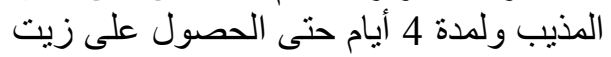

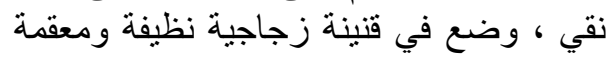
ووضع في الثلاجة الى حين الاستعمال[8]. الكثار جوز الهند:- الكيميائية عن المجاميع الفعالة في حضر محلول من مستخلص الندات من من النبات قبد

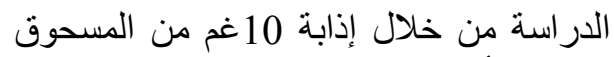
النباتي وأذيب في 50 مل من الماء الماء المقطر المبر

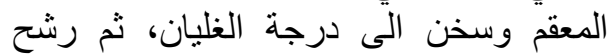
المحلول وترك لييرد ووضع في في بيكر زجاجي

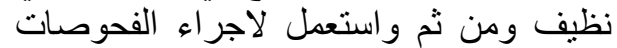

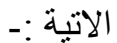

1- الكشف عن التانينات Tannins: أخذ 1 مل من المحلول النباتي المحضر سابقأ

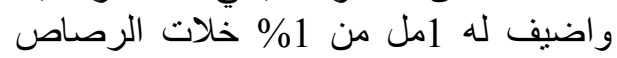

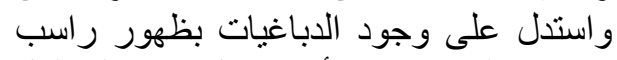

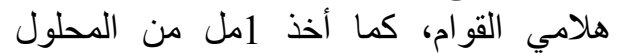

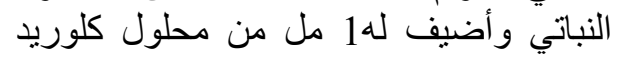
الحديديك 1\% و استدل على وجود الدباغيات

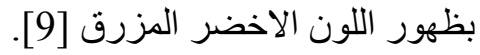

2- الكثف عن الصابونينات Saponins:

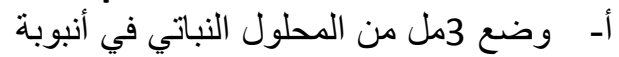

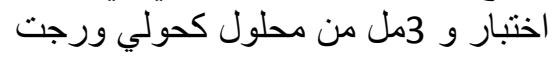

الانبوبة بشدة ،ان ظهور ملتول رغوة كثيفة

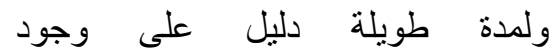

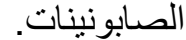

ب- اضيف 1مل من محلول كلوريد الزئبق

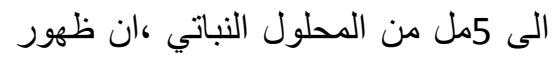

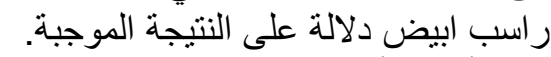

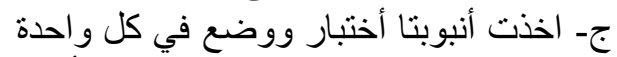

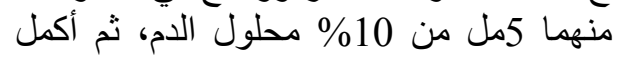

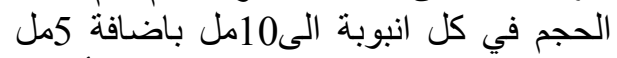

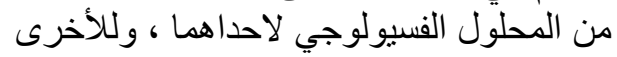

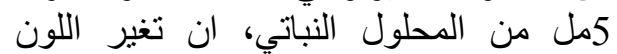
وتحلل كريات الدم الحمر و الذي يتم تأكيده بفص قطرة من كل أنبوب على شريحة زجاجية بوساطة المجهر دلالة على النتيجة الموجبة[10].

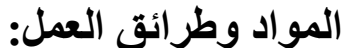

تحضير العينات النباتية:

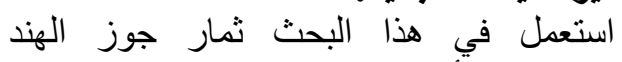
المنو افرة في الآسواق المحلية في مدينة بغداد، ثم غسلت الثمار جيدأ وكسر غلاف الافها الخارجي وأخذت التخ

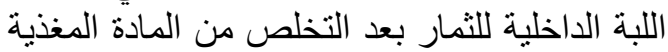

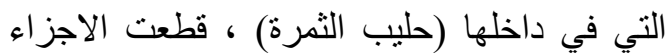

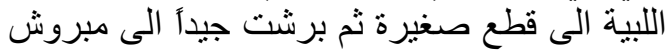
ناعم ثم ووضعت في علبة زجاجية مغلقة ونظيفة البية ومعقمة حفظت في الثناجة الى حين الاستعمال

$$
\text { 1- تحضير المستخلصات النباتية:- }
$$

وزن 50غم من المبروش المئن الناعم من ثمرة

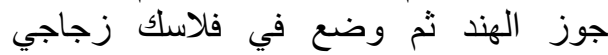

واضيف اليه 50مل من الماء المقطر بدرجة فئة

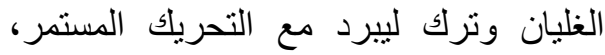
ومن ثم رشح المحلول عبر طبرد ليقات من الثاش ، ثم بورق ترشيح Whatman No.2 الر اشح وبخر بجهاز المبخر الدوار( Rotary عند درجة حرارة 40م ول و الى (eraporator

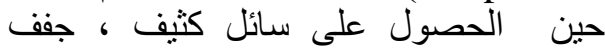

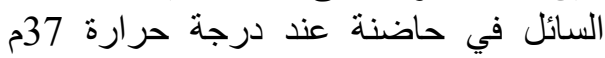
وخلال2- 3 ايام حتى الحصول على مسحوق دران مجف ، جمع المع المسحوق وحفظ في قنينة

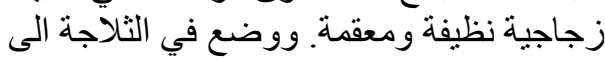
حين الاستعمال[6].

2-تحضير المستخلص الكحولي: وزن 30غم من المبروش الناعم لثمرة جوز

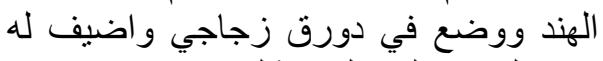

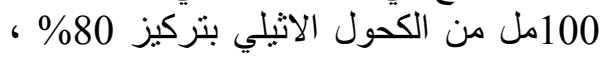

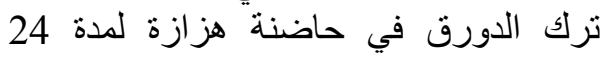

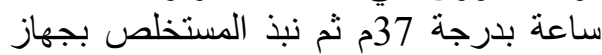

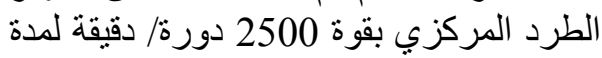

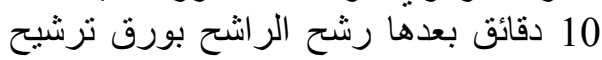
با ثم عرض الر اشح للتبخير

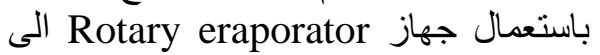
حين الحصول على سائل كثيف ،ثم جفة جلى السائل عند درجة حرارة 37م لمدة 5 ايام

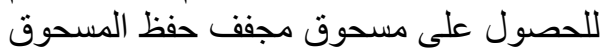

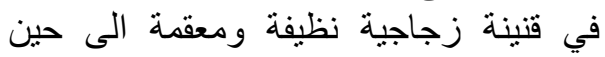

الأستعمال [7].

$$
3 \text {-تحضير المستخلص الزيتي: }
$$

وزن 20 غم من المبروش الناعم جوز المئين الهند ووضع في وعاء ورقي (Thumble) ، فئرون ثم وضع الوعاء الورقي في هاز 
تحضير التراكيز المختلفة للمستخلص المائي

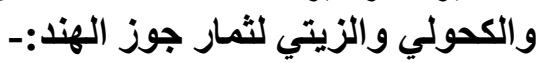

حضرت التراكيز المختلفة للمستخلص التصن (المائي

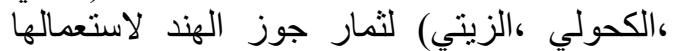
ومعرفة تأثير ها في مجمو عة من الجر اثيم الممرضة لأنية

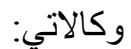
1 - 1 - المستخلص المائي :

حضر محلول خزين (Stock solution ) من

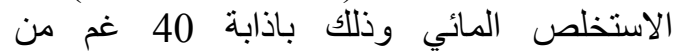
المستخلص المجفف في100مل من الماء المن المقطر المعقم ، رشح المحلول باستعمال اوراق ترشيح

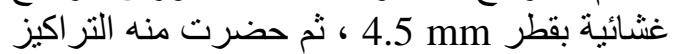
الآتية , 320 160,80, 40 ملغم/مل. 2-المستخلص الكحولي :

حضر محلول خزين( Stock Solution ) من المجلية المستخلص الكحولي وذللك بأذابة 8 غم من السن الكن

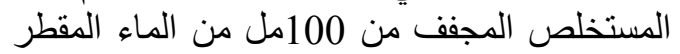

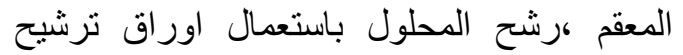

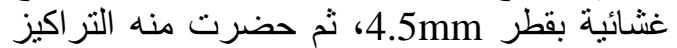
الآتية 8,4, 16 16 , 32 ملغم/ مل . 3-المستخلص الزيتي:

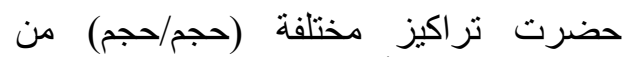

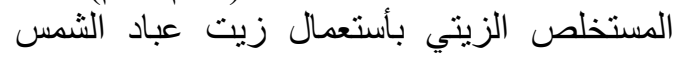
لغرض التخفيف وهذه التر اكيز هي1 زئس : , 1:3 , 1:4 . $1: 2,1$

$$
\text { الجراثيم المستعملة :- المئل }
$$

تم استعمال ستة أنواع من الجراثيم الثماع المرضة

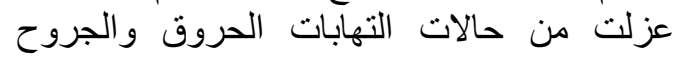
كيث جمعت مسحات من المرضى الاتيث المراجعين

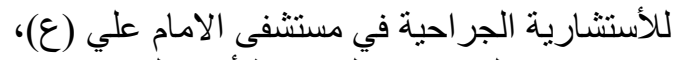

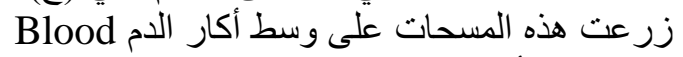
Macconkey agarar agar

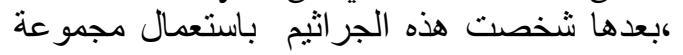

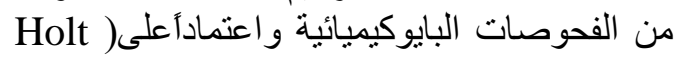

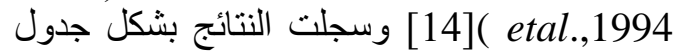

$$
\text { و هذه الجر اثيم هي:- }
$$

Proteus mirabilis , Proteus vulgaris, Staphylococcus aureus,

\section{Pseudomonas aeruginosa}

Burkholderia mallei, Pseudomonas fluorescence.

حضر عالق جرثومي لكل منها من خلال

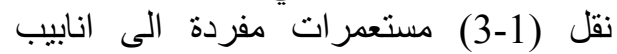

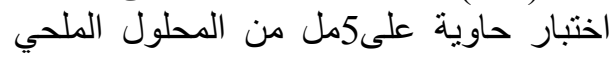

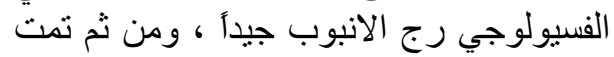
معايرة عكورة الانابيب الحاوية على الائي المعلق

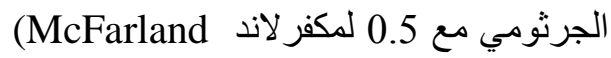

الفلافونويدات

\section{3- الكثف عن \\ :Flavonoids}

اتبعت طريقة (11]) وذللك باذابة 10 غم من المسحوق النباتي في

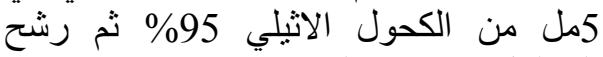
المحلول، و اضيف لله كمية منساوية من مزيج الآيج

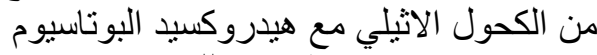

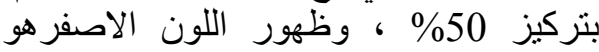
دلالة على ايجابية الكثنف .

4- الكثف عن القلويدات Alkaloids:

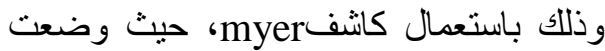

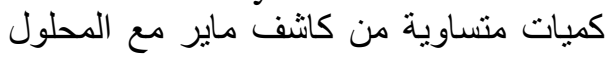

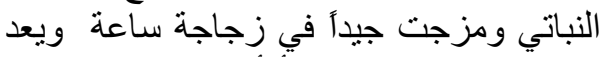
ظهور جزيئات الر اسب ألأبيض هو دهاجئ دلالة على

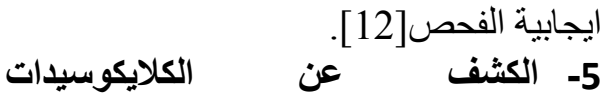
:Glycosides

أخذت كمية من المحلول النباتي ووضعت في في

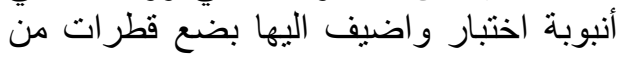

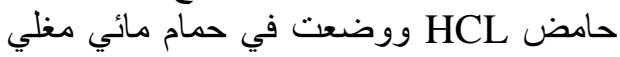

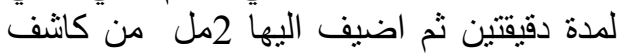
بندكت ووضع المحلول في حمام مائي مغلي

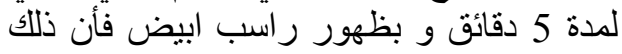
كلالة على ايجابية الفحص [10] 6- الكثف عن التربينات والستيرويدات:

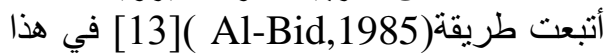

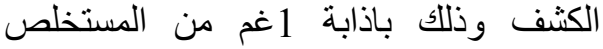
النباتي في قليل من الكلوروفورم (1-2) مل

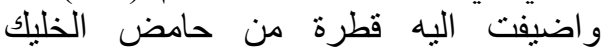
اللامائي وقطرة من حامض الكبرينيك المركز أن ظهور اللون البني دلالة على الكئئ اليجابية

7- الفصدير الأس الهيدروجيني (pH):

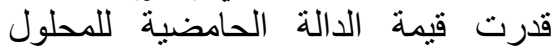
pH النباتي(pH) وذللك باستخدام جهاز عeter عند درجة حرارة المختبر [9].

الكثف عن المجاميع الفعالة في المستخلص النباتي باستعمال جهاز FTIR:-

فضنّا عن اجراء الفحوصنات الكيميائية السابقة

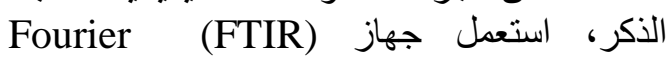
Transform indrared spectrophotometer (shi والمجز من شركة (FTIR- 8300)

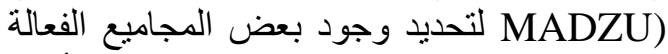

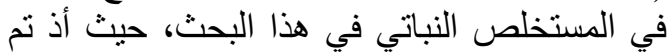
الحصول على منحني بياني وسجلت النتائج بشكل

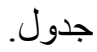


الادنى لكل مستخلص وسجلت النتائج بشكل جدول وأجري التحليل الاحصائي لمعرفة أقل فرق معندي

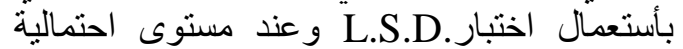

.118] 0.05

\section{النتائج والمناقشة :}

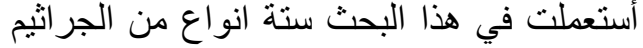

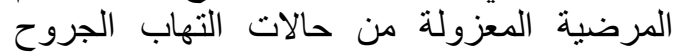

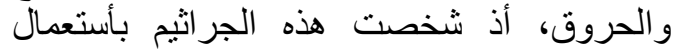

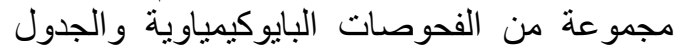

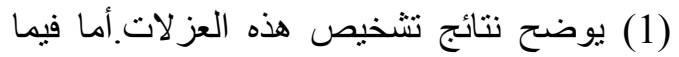

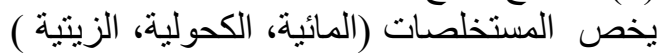
لثمار جوز الهند فقد حضرت نراكيز مختلفة منها، التهات التهات

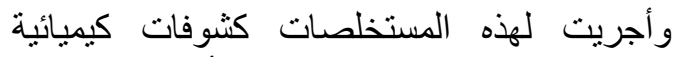
لمعرفة محتواها من المواد الفعالة أذ اشتارت نتات التيائج

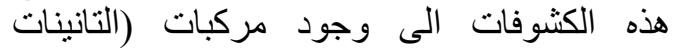
،الصابونبنات، الفلافونويدات، القلويدات ، التربينات ،الستيرويدات) في كل من المستخلصات الفينات (المائية

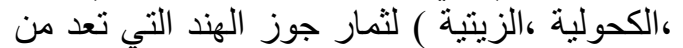

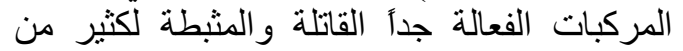

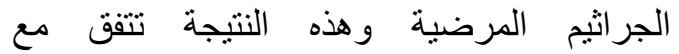
[19]إذ تعرف هذه المركبات (Jammutawi)

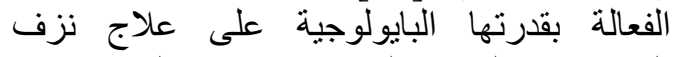

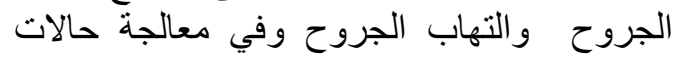

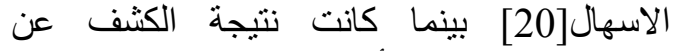
الكلايكوسيدات سالبة أذ ان المستخلصات التئهة (المائية، الكحولية، الزيتية) لثمار جوز الهندالئ أعطت نتيجة

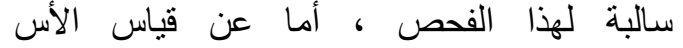

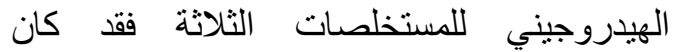
المستخلص المائي ذا أس هيدروجيني (pH 7.0)

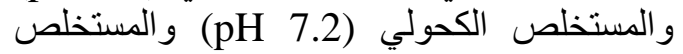

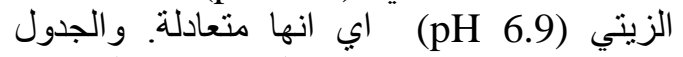
رقم(2) يوضح لتائج الكثوفات الكيميائية للمستخلصات الثلاثة.
Turbidity standard)

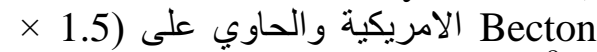
10 10 خلية بكتيرية / مل وذللك لاستعمالها

لاحقأ [15].

تأثير التراكيز المختلفة للمستخلصات

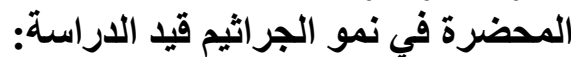

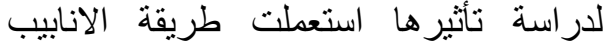
(16] و على النحو الأتي: (tube method)

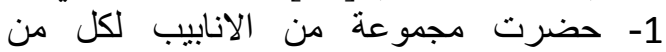

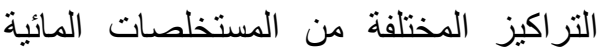
و الكحولية وكذلك الزيتية حيث التئ وضع في في كل

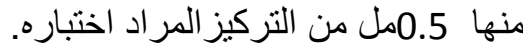

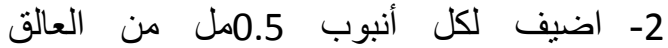
البكتيري المعاير لكل نوع من الجراثيم قيد

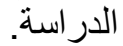

3- حضر أنبوب السبطرة الموجب الذي يحتوي

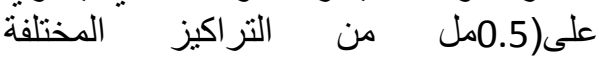

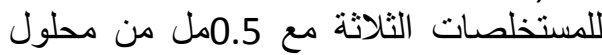
الملح الفسبولوجي)،كما حضر أنبوب السيطرة

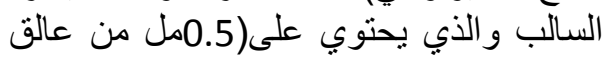

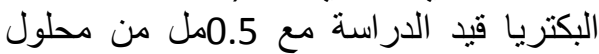
الملح الفسيولوجي) للمقارنة الإنة

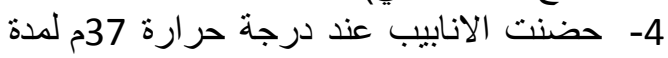
18 ساعة .

5- قرأت النتائج من خلال ملاحظة العكورة ومقارنتها بانبوب السبطرة الموجب و السالب. 6inimum inhibition تحديد Minimum ' concentration (MIC) . bactericidal concentration (MBC)

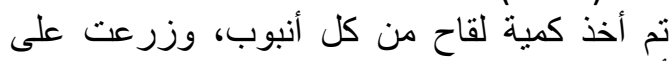

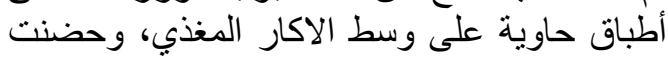

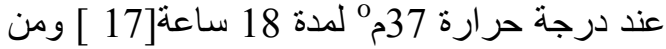
ثم تم حدد التركيز المثبط الادنى والتركيز القاتلت

جدول (1): نتائج الفحوصات الكيموحيوية لتثخيص العزلات البكتيرية قبد الدراسة

\begin{tabular}{|c|c|c|c|c|c|c|c|c|c|c|c|c|c|c|c|c|}
\hline $\begin{array}{l}\text { Gro } \\
\text { wth } \\
\text { at } \\
4 c^{\circ}\end{array}$ & $\begin{array}{c}\text { Gro } \\
\text { wth } \\
\text { at } 42 \mathrm{c} \\
0\end{array}$ & $\begin{array}{c}\text { oxid } \\
\text { ase }\end{array}$ & $\begin{array}{l}\text { catal } \\
\text { ase }\end{array}$ & $\begin{array}{c}\text { coagul } \\
\text { ase }\end{array}$ & $\begin{array}{c}\text { Mannito } \\
1 \\
\text { fermenta } \\
\text { tion }\end{array}$ & $\begin{array}{l}\text { urea } \\
\text { se }\end{array}$ & $\begin{array}{c}\text { Growth } \\
\text { on } \\
\text { blood } \\
\text { agar }\end{array}$ & $\begin{array}{c}\text { motil } \\
\text { ity }\end{array}$ & $\begin{array}{c}\text { Citrate } \\
\text { utilizat } \\
\text { ion }\end{array}$ & $\begin{array}{c}\text { Voges } \\
- \\
\text { proska } \\
\text { uer }\end{array}$ & $\begin{array}{l}\text { Met } \\
\text { hyl } \\
\text { red }\end{array}$ & $\begin{array}{c}\text { Ind } \\
\text { ol }\end{array}$ & $\begin{array}{c}\text { Shap } \\
\text { e of } \\
\text { bacte } \\
\text { rial } \\
\text { cell }\end{array}$ & $\begin{array}{c}\text { Gra } \\
\mathrm{m} \\
\text { stai } \\
\mathrm{n}\end{array}$ & الجرثومة & \\
\hline - & - & - & + & - & - & + & $\begin{array}{c}B- \\
\text { haemol } \\
\text { ysis }\end{array}$ & + & + & - & + & - & $\begin{array}{c}\text { Bacili } \\
\mathrm{i}\end{array}$ & $-\mathrm{ve}$ & $\begin{array}{c}\text { Proteus } \\
\text { mirabilis }\end{array}$ & 1 \\
\hline - & - & - & + & - & - & + & $\begin{array}{c}B- \\
\text { haemol } \\
\text { ysis }\end{array}$ & + & + & - & + & + & $\begin{array}{c}\text { Bacili } \\
\text { i }\end{array}$ & $-\mathrm{ve}$ & $\begin{array}{l}\text { Proteus } \\
\text { vulgaris }\end{array}$ & 2 \\
\hline- & + & - & - & + & + & + & $\begin{array}{c}B- \\
\text { haemol } \\
\text { ysis }\end{array}$ & - & + & + & - & + & Cocci & $+\mathrm{ve}$ & $\begin{array}{c}\text { Staphyloc } \\
\text { occus } \\
\text { aureus }\end{array}$ & 3 \\
\hline- & + & + & + & - & - & - & $\begin{array}{c}B- \\
\text { haemol } \\
\text { ysis }\end{array}$ & + & + & - & - & - & $\begin{array}{c}\text { Bacili } \\
\mathrm{i}\end{array}$ & $-\mathrm{ve}$ & $\begin{array}{c}\text { Pseudomo } \\
\text { nas } \\
\text { aeruginos } \\
a\end{array}$ & 4 \\
\hline- & + & + & + & - & + & - & $\begin{array}{c}B- \\
\text { haemol } \\
\text { ysis }\end{array}$ & - & + & - & + & - & $\begin{array}{c}\text { Bacili } \\
\text { i }\end{array}$ & -ve & $\begin{array}{l}\text { Burkholde } \\
\text { ria mallei }\end{array}$ & 5 \\
\hline+ & - & + & + & - & - & - & $\begin{array}{c}B- \\
\text { haemol } \\
\text { ysis }\end{array}$ & - & + & - & - & - & $\begin{array}{c}\text { Bacili } \\
\text { i }\end{array}$ & $-\mathrm{ve}$ & $\begin{array}{c}\text { Pseudomo } \\
\text { nas } \\
\text { fluorescen } \\
\text { ce }\end{array}$ & 6 \\
\hline
\end{tabular}


عند دراسة تأثير التراكيز المختلفة للمستخلصات الثناثة لثمار جوز الهند في الجراثير الثيم الممرضة لئنة المعزولة من التهابات الجروح و الحروق فقد ثبت التبن ان المستخلص (المائي، الكحولي، الزيني) بتر اكيزه المختلفة المستخدمة في هذا البحث لـ لم يؤثر في

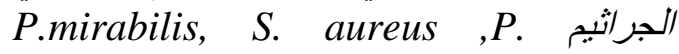
aeruginosa الفعالة (كما اثتتت نتائج الكثوفات الكيميائية وتحليل

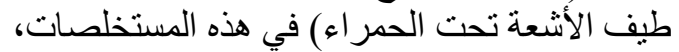

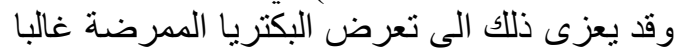

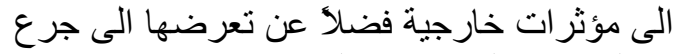
مختلفة من المضادات الحياتية في اثناء احداثها

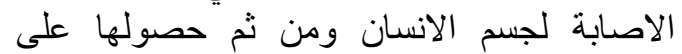
المقاومة نتيجة لامتلاكها كروموسومات مقات مقلومة الإنة

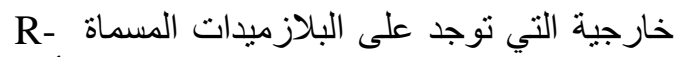

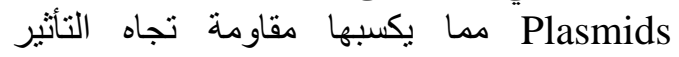

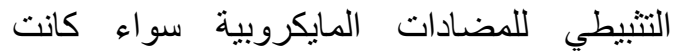

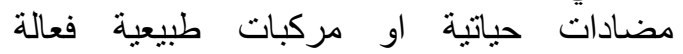

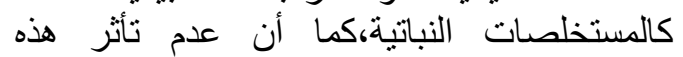

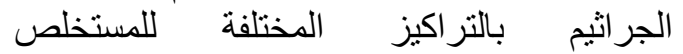
(المائي،الكحولي،الزيتي) قد يعود الى طبيعة البناء

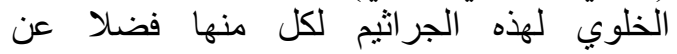
الميكانيكية التي تسلكها في مقاومة المئي المؤثرات الخارجية كالمركبات الفعالة الموجودة في هذهاته

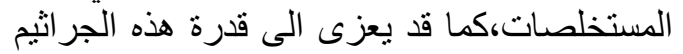
على انتاج انزيمات ايضية لها القدرة على لفئ تحطيم هذه

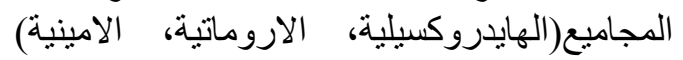

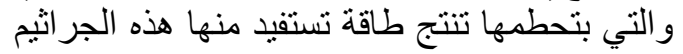

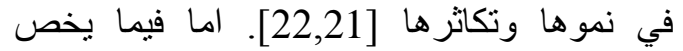
بكتريا Proteus vulgaris فقد كان التركيز 80 ملغم/مل من المستخلص المائي هو التركيز المثبط لتهي

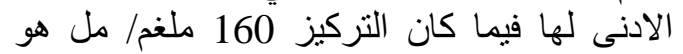

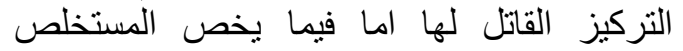
الكحولي فقد كان تركيز 4 ملغم/ مل هو لهو التركيز

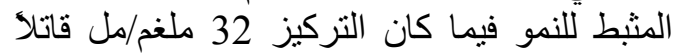

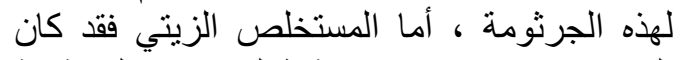

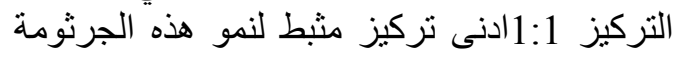

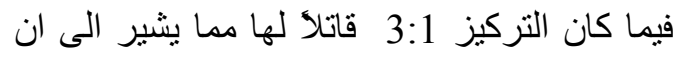

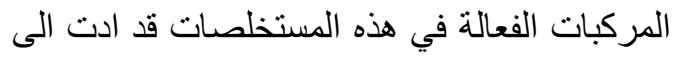
تثبيط فعال لهذه الجرثومة.

في حين ان نمو الجرثومة Burkholderia mallei

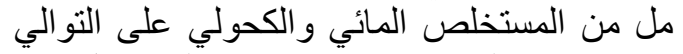

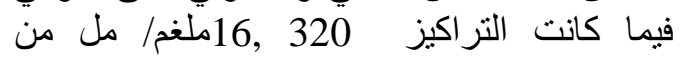

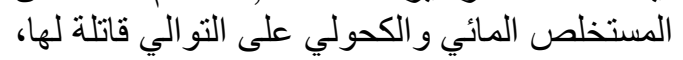

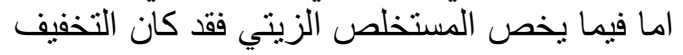

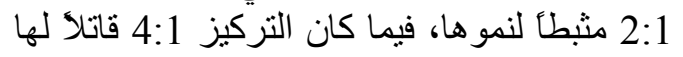

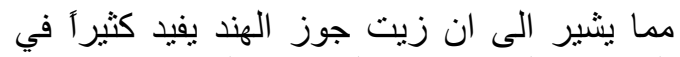
التهابات الجروح والحروق التي تسبيها هذه فئ
جلول (2) : نتائج الكشوفات الكيميائية النوعية

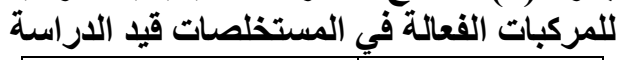

\begin{tabular}{|c|c|c|c|}
\hline \multicolumn{3}{|c|}{ مستخلص ثمار جوز الهند } & \multirow{2}{*}{ المركب الفعال } \\
\hline الزيتي & الكحولي & 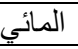 & \\
\hline+ & + & + & التانينات \\
\hline+ & + & + & الصـابو نينات \\
\hline+ & + & + & الفلافونويدات \\
\hline+ & + & + & القلويدات \\
\hline+ & + & + & والستيرويدات \\
\hline- & - & - & الكلايكو سيدات \\
\hline
\end{tabular}

اما فيما يخص الكثف عن المجاميع الفعالة

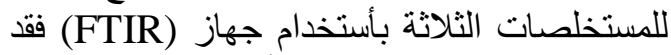

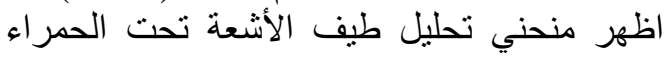

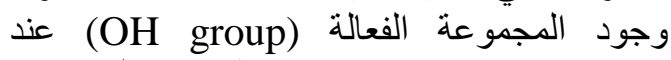
الامتصاصية (3500) كما ظهرد الإنة المجموعة

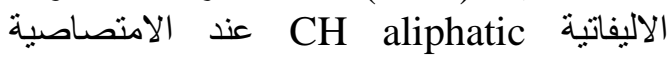
كما نجد ظهورا متميز الأهنيا

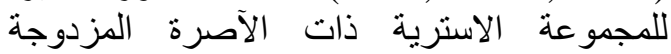

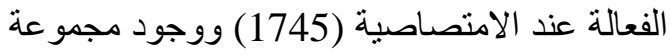
الامينات (N = C) في موقعين عند الامتصاصية

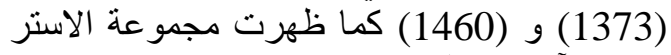

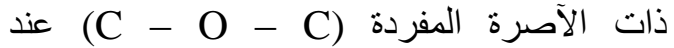
الامتصاصية 1109 و 1159 كما نلاحظ وجود

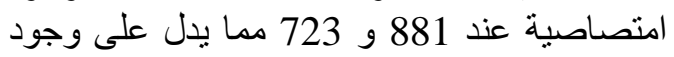

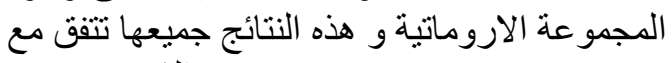

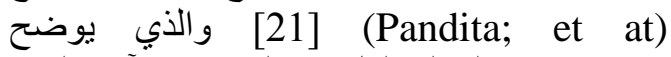
الامتصاصية المثالية لكل من المجاميع الآنفة الذكر وفضلا عن ذلك فان نتائج الكثوفية الكات الكئية الكيميائية

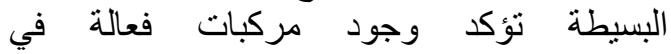
المستخلصات (المائية ، الكحولية، الزيتية) لثمار فئيل جوز الهند والثكل (1) يوضح منحني تحليل طيف التهن الأشعة تحت الحمر اء.

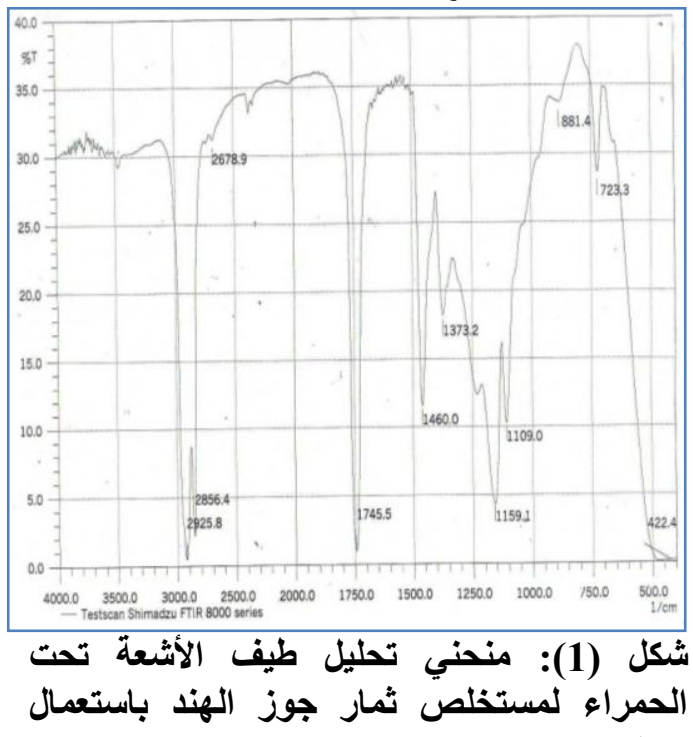

جهاز (FTIR) 


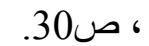

7.زوكيان، سيلفا انترانيك3005. دراسة الفعالية البيولوجية للمستخلصين المائي و والكحولي لئي Equisetum لنبات ذنب الخيل الحملية المعة Larvense L.

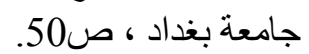

8.السامر ائي ، اياد ، صالح مخلف،2000. تأثير

السماد "النيتروجيني في نمو وحاصل فياد الزيت

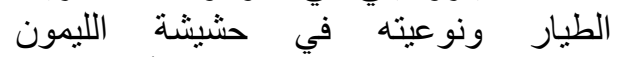
Lymbopogon citrates L. الطيار في نمو عدد من الفطريات ـ اطروحة الطيات دكتور اه ـ.كلية العلوم ، جامعة بغداد.

9. Shihata, I,M.1951. Apharmacological study of Anagollis avrensis. M.D.Vet. Thesis. Cairo university lcollage of science.

10. Evans, W.C.1999. Trease and Evans Pharmacognosy. London. Philadelphia. Baillieve Tindall.

11. Jaffer, H.J., Mahmod, M.J., Jwad, A.M.; Naji, A. and Al- Nab, A.1983. Phytochemical and biological screening of some Iraqi plants. Fitoterapia, Lix,p. 299.

12. Fuhrman, B.; Rosenblat, M.; Tlayek, T.; Colemon, K. and Aviram, M.2000. Ginger extract consumption reducesplasma, cholesterol. The medical sciences and Ramabam Medical center. Palestinc; 130:1124- 1131.

13. Al- Bid, M.R.1985. Zuuzusame mestarung der Abschla B membrare in phoenix dactyllifera. Wurzzburg university, Wuzzburg F.R.of Germany.

14. Holt, J.G.; Krieg, N. R. and Sneath, P.A.1994. Bergy's Manual of Determinatine Bacteriology $9^{\text {th }}$ ed. Editedby Williams and wilkins libravy of congress catdoging, baltimors.

15. Baron,E.J. and Fanegold, S.M.1990 Diagnostic microbiology and laboratory method of basic microbiology. $8^{\text {th }}$ ed. C.V mosby. USA.

16. National committee for clinical laboratory Standards. 2003.
الجرثومة والتي تتميز بمقاومنها العالية للمضادات

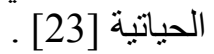

اما فيما يخص جرثئ fluorescence مل من المستخلص المائي والكحولي على التى التوان التي

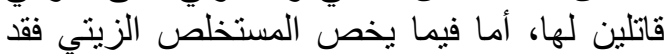
كان التركيز 2:1 مثبطا لها، فيما كان التركيز التهي التهي قاتلا لها مما يعطي أمكانية استعمال زيمان زيت لتركيز جوز

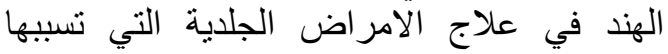
الجرثومة. و الجدول (3) يوضح هذه النتائج .

جدول (3) : نتائج اختبار MBC, MIC ضد الجراثيم الممرضة قيّ الدراسة

\begin{tabular}{|c|c|c|c|c|c|c|}
\hline \multicolumn{2}{|c|}{ الزمتنظص } & \multicolumn{2}{|c|}{ المستخلص الكحولي* } & \multicolumn{2}{|c|}{ المستخلص المائي* } & \multirow{2}{*}{ الكائن المجهري } \\
\hline MBC & MIC & $\begin{array}{c}\mathrm{MBC} \\
\mathrm{Mg} / \mathrm{ml}\end{array}$ & $\begin{array}{c}\mathrm{MIC} \\
\mathrm{Mg} / \mathrm{ml} \\
\end{array}$ & $\begin{array}{r}\mathrm{MBC} \\
\mathrm{Mg} / \mathrm{ml} \\
\end{array}$ & $\begin{array}{c}\mathrm{MIC} \\
\mathrm{Mg} / \mathrm{ml} \\
\end{array}$ & \\
\hline - & - & - & - & - & - & $\begin{array}{c}\text { Proteus } \\
\text { mirabilis }\end{array}$ \\
\hline $3: 1$ & $1: 1$ & 32 & 4 & 160 & 80 & Proteus vulgari. \\
\hline - & - & - & - & - & - & $\begin{array}{l}\text { Pseudomonas } \\
\text { aeruginosa }\end{array}$ \\
\hline & - & - & - & - & - & $\begin{array}{c}\text { Staphylococcus } \\
\text { aureus }\end{array}$ \\
\hline $4: 1$ & $2: 1$ & 16 & 4 & 320 & 40 & $\begin{array}{c}\text { Burkholderia } \\
\text { mallei }\end{array}$ \\
\hline $3: 1$ & $2: 1$ & 32 & 4 & 160 & 80 & $\begin{array}{l}\text { Pseudomonas } \\
\text { fluorescence }\end{array}$ \\
\hline
\end{tabular}

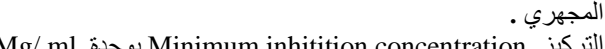
التركيز : المجيط : MIC

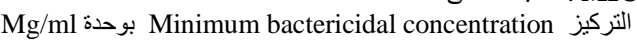
MBC MIC اذ أن(P M.D

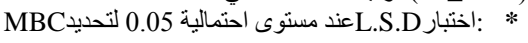

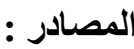

1.Mohd, A.A.R.2004.FRIM Infocus, Aquatery of the forest Research , Institute of Malysia.

2. Atlas , R.M.;Parks,L.C. and Brown, A.E.1995. Laboratory Mannual of Expermantal Microbiology. Mosby -Yearbook,Baltimore.

3. Solberg, Y.2011. The biological effects of coconut oil. Indian. $\mathbf{J}$. pharmacology. 30:20-24.

4. الثماع ، علي عبد الحسين .1989. العباء العقاقير وكيمياء النباتات الطبية. دار الكتب للطباعة الطبات

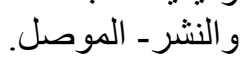

5. The Japanes Phavmacopoeia 1996.

Ministry of Health and welfave.

XIII.Toxyo.PP.275.

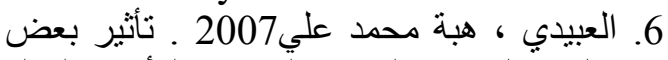

المستخلصات النباتية المضادة للأميبا الحالة

للنسيج Entamoeba histolytica

على اوساط زرعية ـ رسالة ماجستير ، كلية العلوم، جامعة بغداد العزاد 
20. Dastur, J.F.1970. Medical plant of India \& Pakistan. 1et ed., Regional Research Lab., Bombay, India. P:150-155.

21. Pandita, K.; Bhatia, M.S.; Thappa, R.K. and Dhar, K.L.1983. Sesonal Variation of active compound of some medical plants. J. of planta medica, 48,: (81-82).

22. Bertram, G. and Anthony, J.1993 pharmacology(examination and board Reviw). Appleton and Lange. Los. AHos- CaliforniaUSA.P: 267- 270.

23. Mark Estes, D. , Dow ,S.D., Schweizer ,H.P. and Torres, A.G.2010. Present and future therapeutic strategies melioidosis and glanders. Ezpert. Rev. Anti.Infect. Ther. 8(3):325-338.
Approved Standard: M7-A6. Methods for dilution antimicronial Susceptiblity test for bacteria that grow aerobically, $6^{\text {th }}$ ed. National committee for clinimal laboratory standamds, wayne, pa.

17. Koneman, E.W.; Allen, S.D.; Jawa, W.M. and Sachrecheber, P.C. 1997.Color Atlas and text book of Diagnostic Microbiocogy. $8^{\text {th }}$ ed. Philadelphia.

18.الر اوي، خاشع محمد1986. مبادئ الاحصاء. وزارة التعليم العالي والبحث العلمي/جامعة الاحة

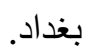

19. Indian herbal pharmacopoeia, (Vol.I),1998. Ajoint publication of Regional Research laboratory, council of scientific \& Industrial Research . Jammutawi.P:1-10.

\title{
Effect of Aquatic, Alcoholic and Oily Extracts of Cocos nucifera L.on the Growth of Certain Pathogenic Bacteria Isolated from Wounds and Burns Infections
}

\section{Hala Mouyed Radif*}

*University of Baghdad / college of science/ Department of Biology

\begin{abstract}
:
Three types of extracts ( aquatic, alcoholic, and oily ) were prepared from the fruits of coconuts, and a series of chemical tests were conducted in addition to the use of the FTIR equipment to determine the active locations in the prepared extracts.

The results indicated the presence of active compounds (tannins, saponins, flavonoids, turbines and steroids) in the extracts prepared from the fruits of coconuts, also the antimicrobial capability of these extracts were tested on pathogenic bacteria isolated from wounds and burns infections cases.

The results proved that the concentration $80 \mathrm{mg} / \mathrm{ml}$ of the aquatic extract is the minimum inhibitory concentration for the microbes: Proteus vulgaris and Pseudomonas fluorescence, while the concentration of $160 \mathrm{mg} / \mathrm{ml}$ is the lethal concentration for them, as for the alcoholic extract the concentration of $4 \mathrm{mg} / \mathrm{ml}$ was the minimum inhibitory concentration for these two microbes, while the concentration of $32 \mathrm{mg} / \mathrm{ml}$ was the lethal concentration to them, as for the oily extract the two concentrations of $1: 1$ and 1:3 were the minimum inhibitory concentration and the lethal concentration respectively for these two microbes, while for the Burkhorderia mallei microbe the concentrations of 40, 4, 6,2:1 of the aquatic, alcoholic and oily extracts respectively were the minimum inhibitory concentrations for their growth, while the concentrations 160,32,3:1 of the aquatic, alcohol and oily extract respectively the lethal concentrations to them.
\end{abstract}

